\title{
Analysis of Dielectric Response Measurements for Condition Assessment of Oil-Paper in Power Transformer Insulation
}

\author{
Antonio Tome Mandala*, Zhang Tao", Jiang Shiejie*, Zhang Ning* \\ * Department of Electrical Engineering and Renewable Energy \\ China Three Gorges University \\ DOI: 10.29322/IJSRP.11.05.2021.p11318 \\ http://dx.doi.org/10.29322/IJSRP.11.05.2021.p11318
}

\begin{abstract}
In this paper, the oil-paper insulation system of the power transformer is analyzed in the frequency domain. Different factors that influence the dielectric insulation of oilpaper, such as the temperature, moisture in cellulose, conductivity, and oil aging, are described. The analysis for the dielectric response is carried out by analyzing the dissipation factors and the complex capacitance through the Frequency Domain Spectroscopy (FDS) method. This tool analyzes the dielectric responses of the oil-paper insulation system, by measuring a series of dissipation factors at different frequencies, typically distributed over the range of $0.001 \mathrm{~Hz}$ to $1000 \mathrm{~Hz}$. The result of the experiments shows that the temperatures, moisture in cellulose, conductivity, and oil aging have a significant influence, in the low-frequency range than in the high-frequency range.
\end{abstract}

Index Terms- Frequency Domain Spectroscopy (FDS), dissipation factor, temperature influence, moisture in cellulose, conductivity, oil aging.

\section{INTRODUCTION}

$\mathrm{I}_{\mathrm{in}}$ $\mathrm{n}$ recent years, diagnostics to determine the state of the insulation system of a power transformer has become increasingly important due to technical and economic reasons $[1,2]$. The power transformer is the most important and expensive equipment in the power system, therefore, it is necessary to know the state of the insulation system in order to plan future preventive maintenance and prevent possible equipment failure. The insulation system is basically constituted of cellulose and oil, factors such as moisture, temperature, oil conductivity and aging have greatly influenced for reduction of the insulation [1-3]. The main methods to measure the dielectric response in the power transformer are Polarization Depolarization Current (PDC) and Recovery Voltage Measurements (RVM), which are in the time domain; whereas, Frequency Domain Spectroscopy (FDS) represents the frequency domain [4-7]. The FDS method presents a small influence from electromagnetic noise than PDC and RVM, and the obtained results are more reliable $[8,9]$. This article aims to analyze how factors such as moisture, temperature, oil conductivity, and aging influence in dielectric responses using the FDS method.

\section{PRINCIPLE OF DIELECTRIC FREQUENCY}

\section{RESPONSE}

When the external electrical field $\mathrm{E}(\mathrm{t})$ is applied in a dielectric material, the material became polarized and the density current according to Maxwell is equal to [10-14]:

$$
\mathrm{J}(\mathrm{t})=\sigma_{0} \mathrm{E}(\mathrm{t})+\frac{d D(t)}{d t}
$$

Where: $\sigma 0$ is the dc conductivity of the dielectric material, and $\mathrm{D}(\mathrm{t})$ is dielectric induction. The $\mathrm{D}(\mathrm{t})$ is equal to:

$$
\mathrm{D}(\mathrm{t})=\varepsilon_{0} E(t)+P(t)
$$

Where: $\mathrm{P}(\mathrm{t})$ is polarization, $\varepsilon_{0}$ is permittivity in the vacuum. In the frequency domain the polarization will be [7-9]:

$$
\mathrm{P}(\omega)=\varepsilon_{0}\left[\varepsilon_{\infty}-1+\chi(\omega)\right] E(\omega)
$$

Rewrite equation (1) in frequency domain applying Fourier transform it will be:

$$
\mathrm{J}(\omega)=\sigma_{0} \mathrm{E}(\omega)+\mathrm{J} \omega \mathrm{D}(\omega)
$$

Using equations (1) and (2) in (4), the current density is equal to:

$$
\begin{aligned}
& \mathrm{J}(\omega)=\mathrm{j} \omega \varepsilon_{0}\left\{\varepsilon_{\infty}+\chi^{\prime}(\omega)-j\left[\frac{\sigma_{0}}{\varepsilon_{0} \omega}+\chi^{\prime \prime}(\omega)\right]\right\} E(\omega) \\
& \mathrm{J}(\omega)=\mathrm{j} \omega \varepsilon_{0}\left\{\varepsilon^{\prime}(\omega)-j \varepsilon^{\prime \prime}(\omega)\right\} E(\omega)
\end{aligned}
$$

Where: $\varepsilon^{\prime}(\omega)$ is the real part of the complex permittivity $\varepsilon(\omega)$ (doesn't contribute to power loss) and $\varepsilon^{\prime \prime}(\omega)$ is the imaginary part of the complex (contribute to the power loss). Equation (5) rewritten in terms of capacitance will be [15-17]:

$$
\begin{gathered}
\mathrm{I}(\omega)=\mathrm{j} \omega C_{0}\left\{\varepsilon_{\infty}+\chi^{\prime}(\omega)-j\left[\frac{\sigma_{0}}{\varepsilon_{0} \omega}+\chi^{\prime \prime}(\omega)\right]\right\} U(\omega) \\
\mathrm{I}(\omega)=\mathrm{j} \omega\left\{C^{\prime}(\omega)-j C^{\prime \prime}(\omega)\right\} U(\omega)=j \omega C(\omega) U(\omega)
\end{gathered}
$$

Where: $\mathrm{C}_{0}$ is the geometrical capacitance, $\mathrm{I}(\omega)$ is the response current, $U(\omega)$ is the voltage, $C^{\prime}(\omega)$ is the real part and $C^{\prime \prime}(\omega)$ is the imaginary part of the complex capacitance. The effects of moisture content, Aging effects, and temperature in the insulation system of power transformer will change these quantities in the 
different frequency range $[18,19]$. The Dissipation Factor represents the dielectric loss (DF), when high is the dissipation factor the more are the electrical losses. [10]:

$$
\mathrm{DF}=\tan (\delta)=\frac{\varepsilon^{\prime \prime}}{\varepsilon^{\prime}}=\frac{C^{\prime \prime}}{C^{\prime}}
$$

\section{FREQUENCY DOMAIN SPECTROSCOPY (FDS)}

The FDS method is performed, by measuring a series of dissipation factor measurements at different frequencies, typically from $1 \mathrm{mHz}$ to $1 \mathrm{kHz}$ as shown in the curves of the figure (1) $[12,20]$.The dielectric response is carried out by analyzing the dissipation factors and the complex capacitance.

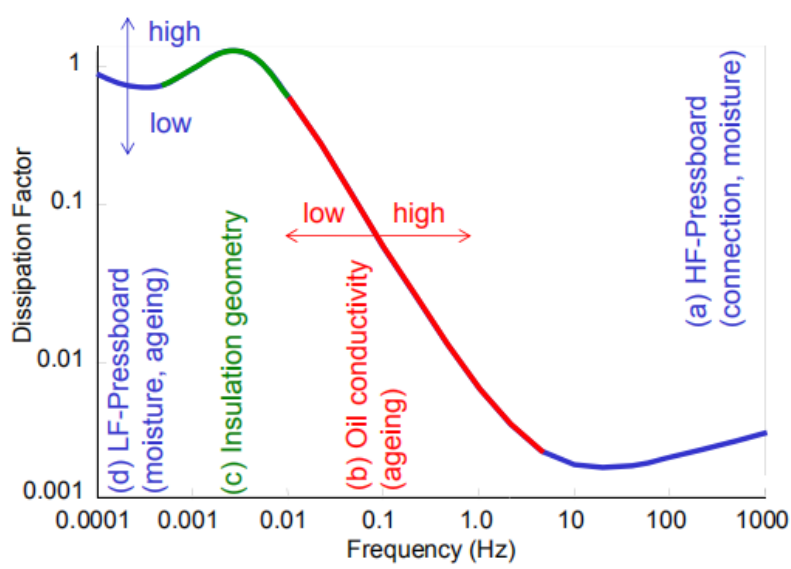

Fig.1 Typical curve of dissipation factor [14, 15, 16].

\section{IV.EXPERIMENTAL LABORATORY TEST}

\subsection{Materials}

To carry out the experiments and to verify the different behavior of the oil-paper in the insulation system, the vegetable oil and paper with a good degree of polymerization were used. The temperature of $120^{\circ} \mathrm{C}$ was used to accelerate the oil aging process by using an oven shown in figure 2 (b). The dielectric response curves were obtained by Megger IDAX 300 figure 2 (c). The vat with three electrodes, for modeling the oil-paper insulation system of the power transformer as shown in figure 2 (a) and the setup of the test system as shown in figure (3).

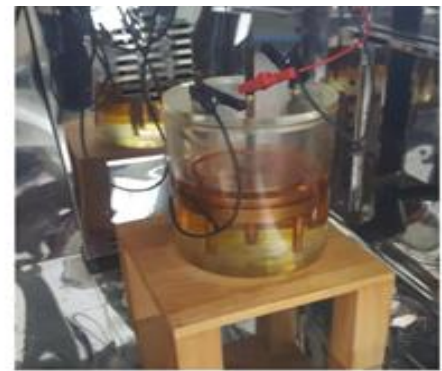

a)

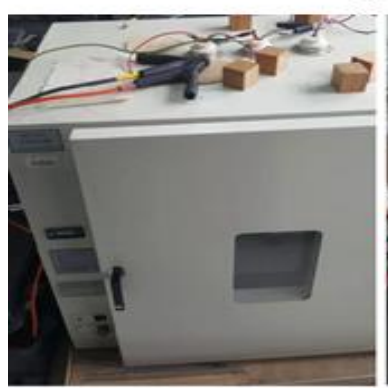

b)

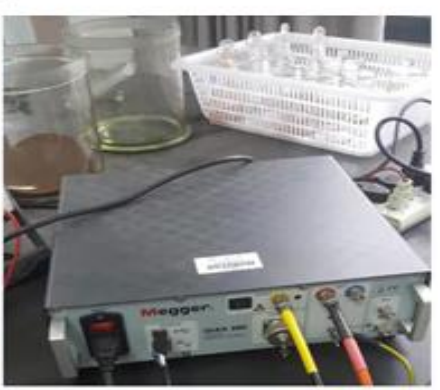

c)
Fig. 2 a) Vat white 3 electrodes, b) oven, c) Megger IDAX 300.

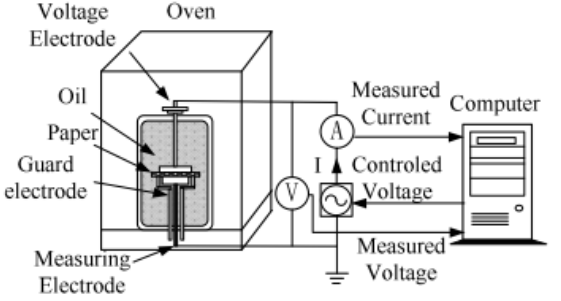

Fig.3 The setup of the test system.

\subsection{Experimental results analysis}

To understand the influence of conductivity, cellulose, humidity, and oil aging in oil-paper insulation behaviors were analyzed, through the complex capacitance (real and imaginary part), and the dissipation factor in the different frequency domain.

\subsubsection{The influence of temperature}

Increasing the temperature of the power transformer reduces the dielectric properties of the insulation. The figures (4) and (5) show the different dielectric responses of capacitance and dissipation factor with different temperatures. It can be seen that the effect of the increase in temperature has a greater influence on low frequencies. When the temperature increases, the dissipation factor also increases with the frequency variation. 


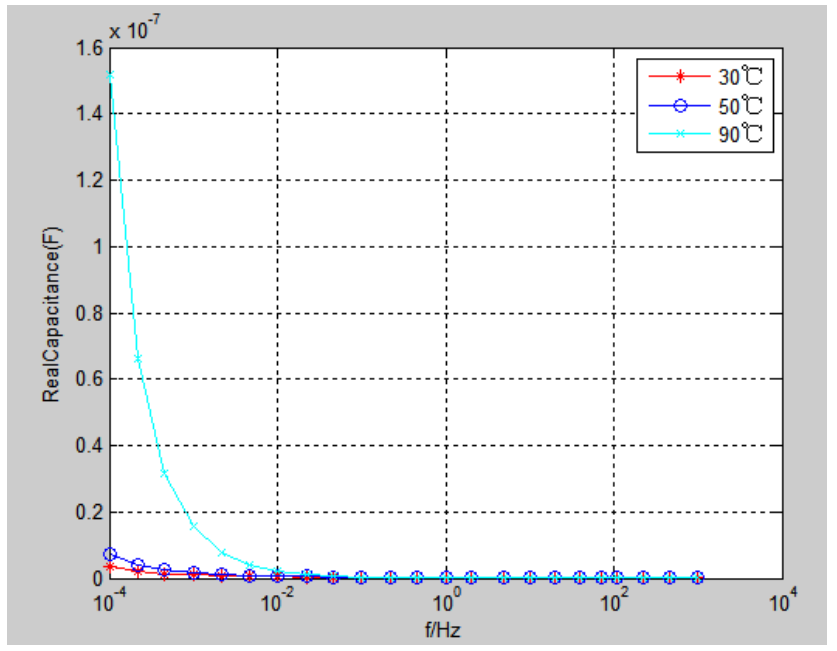

a) Real part of capacitance in different temperatures.

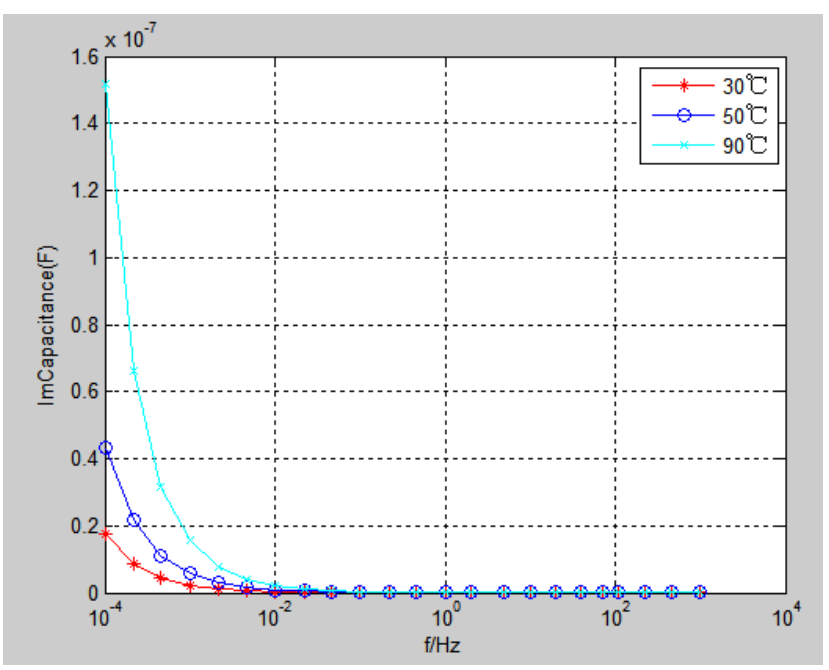

b) The Imaginary part of capacitance in different temperatures

Fig.4 Complex capacitance in different temperatures.

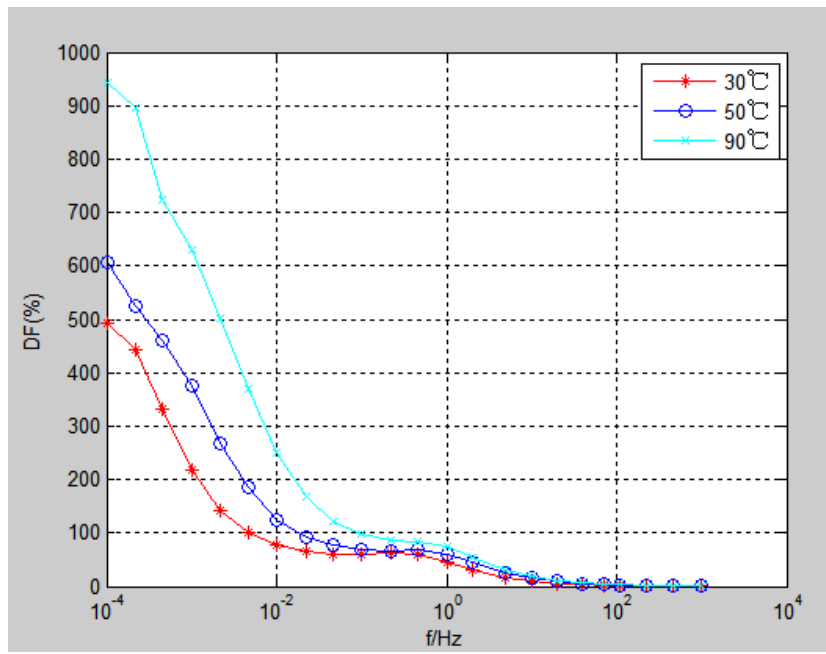

Fig.5 Dissipation factor in different temperatures.

\subsubsection{The influence of moisture on cellulose}

The water content in the insulation system continuously increases due to moisture ingress from the atmosphere, either through the loss of transformer tank tightness, leakage by the joints or welds, as well as poor conservation of silica gel and degradation of the insulation system (cellulose and oil) [20,21,22]. Water in the insulation system (oil-paper) causes dangerous effects such as accelerated cellulose aging, emission of bubbles, and a decrease in dielectric withstand strength.

Moisture increases the losses in power transformers. Figures (6) and (7) show different dielectric responses for different moisture in cellulose, keeping the temperature constant. In the graphs of capacitance and dissipation factors, it can be seen that the increase in cellulose moisture has great effects at low frequencies. It increases the capacitance (mainly, the imaginary component that reflects the dielectric losses), and consequently, the increase in the dissipation factor and this effect is not noticeable for high frequencies. With the increase in moisture in the cellulose, the capacitance and dissipation factor graphs tend to shift to the right with an increase in frequency.

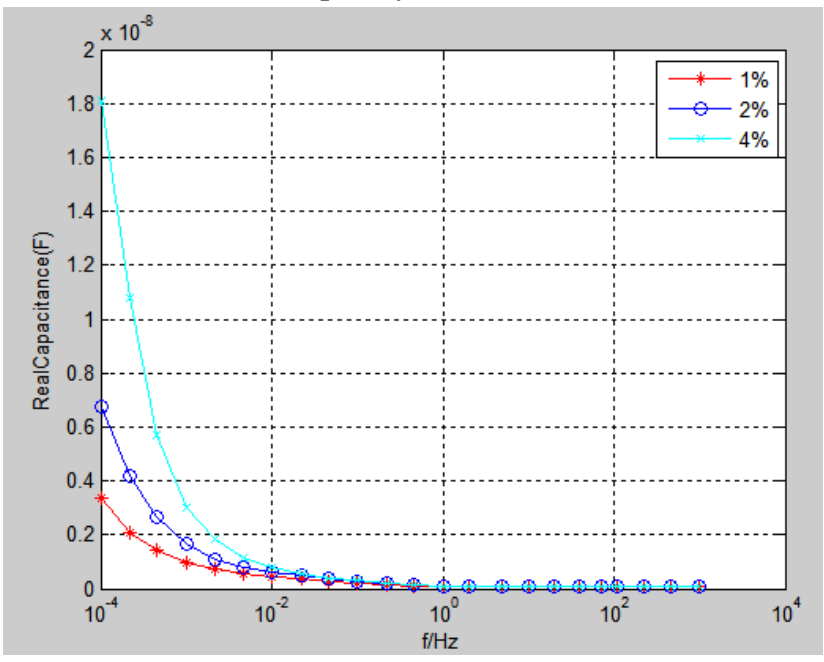

a) The real part of capacitance with different moisture content in cellulose

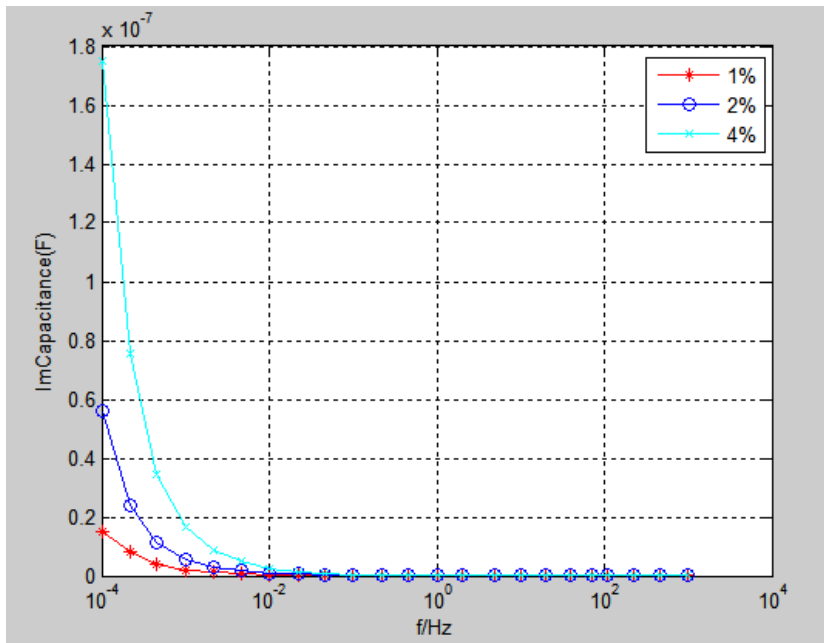


b) The Imaginary part of capacitance with different moisture content in cellulose.

Fig. 6 Complex capacitance with different moisture content in cellulose.

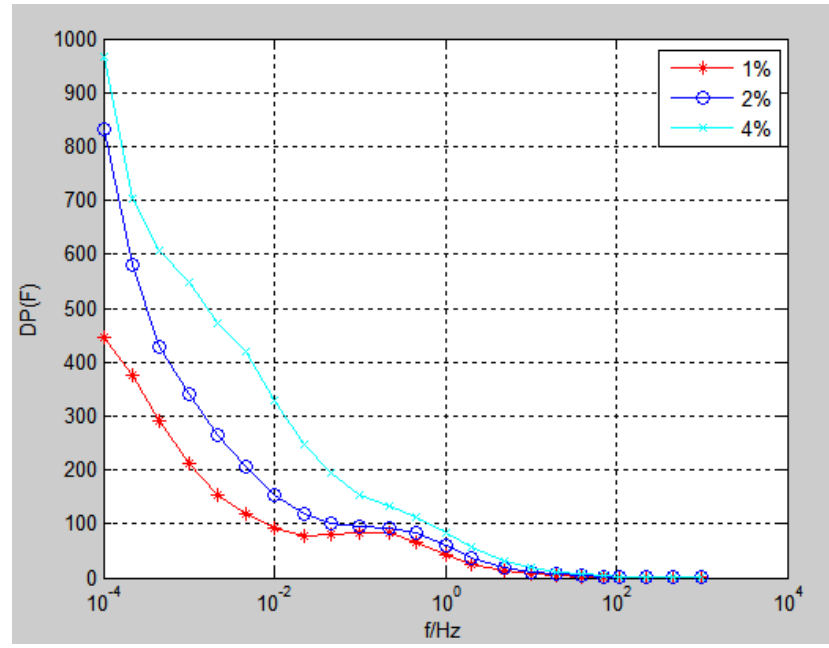

Fig. 7 Dissipation factor with different moisture.

\subsubsection{The influence of oil conductivity}

The process of oil deterioration occurs when oxygen from the air dissolved in this liquid and released by the oxidation of the insulating paper.This is accompanied by the water brought on the surface by the humidity of the air or released by the oxidation of cellulose.This comes into contact as an insulating oil and, from catalysts (such as copper and iron) and accelerators (heat, high voltage, vibration, and electrical surges) initiate the process in which soluble, mainly acidic, products are formed.As the process continues, the soluble products formed become insoluble, which in turn will compose the sediment that causes the dielectric acidity of the oil to be lost and consequently increases the conductivity [23,24].

The graphs in figures (8) and (9) show that the effect of the increase in conductivity of the oil affects the dielectric response, especially at low frequencies $(1 \mathrm{mH}$ to $10 \mathrm{~Hz})$. Moreover, the increase in capacitance and the dissipation factor is verified from the constant moisture in the cellulose in the order of 2 to $2.1 \%$. The graphs of capacitance and the dissipation factor tend to shift to the right with an increasing frequency. Furthermore, the conductivity increases the dielectric losses in the transformer due to the loss of dielectric stiffness in the insulating oil.

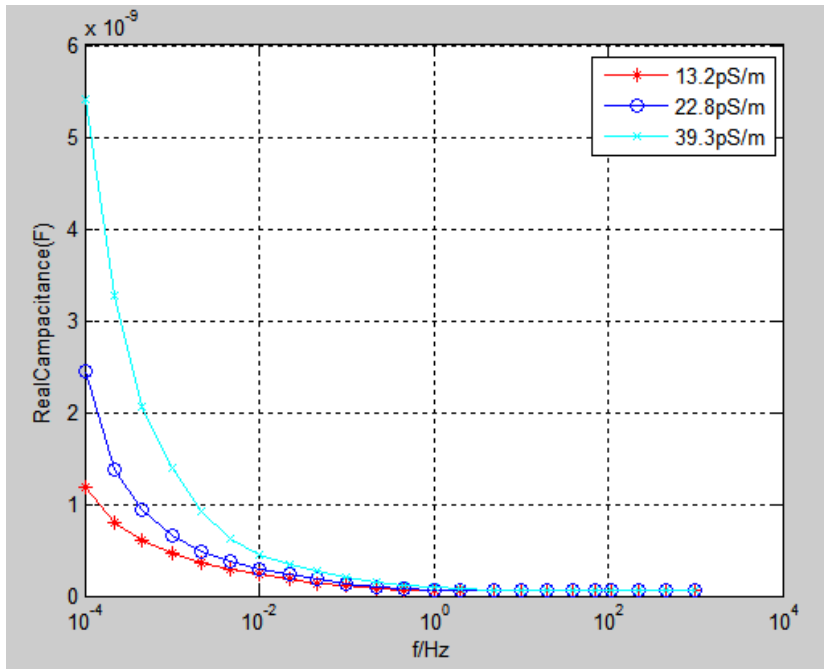

a) The real part of capacitance with different oil conductivity.

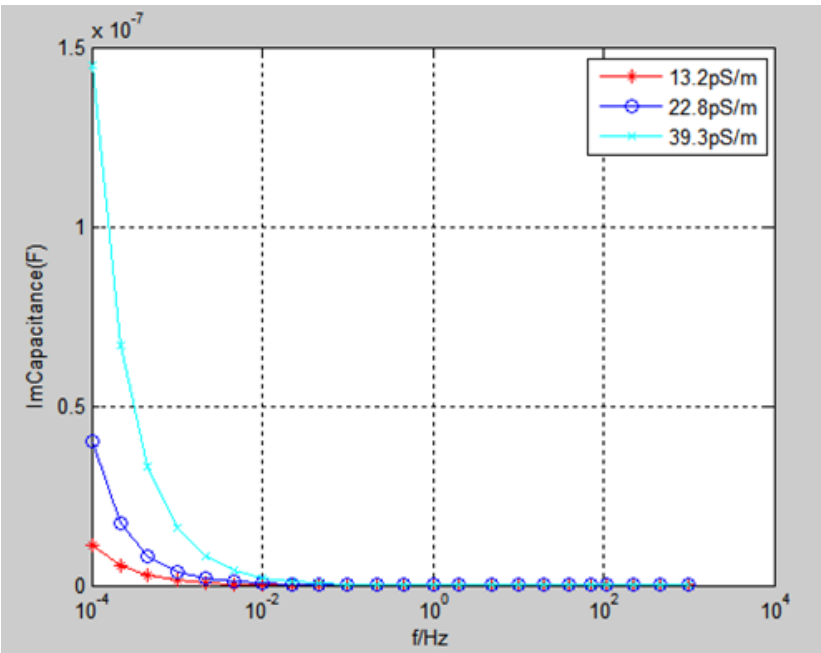

b) The imaginary part of capacitance with different oil conductivity

Fig.8 Complex capacitance with different oil conductivity.

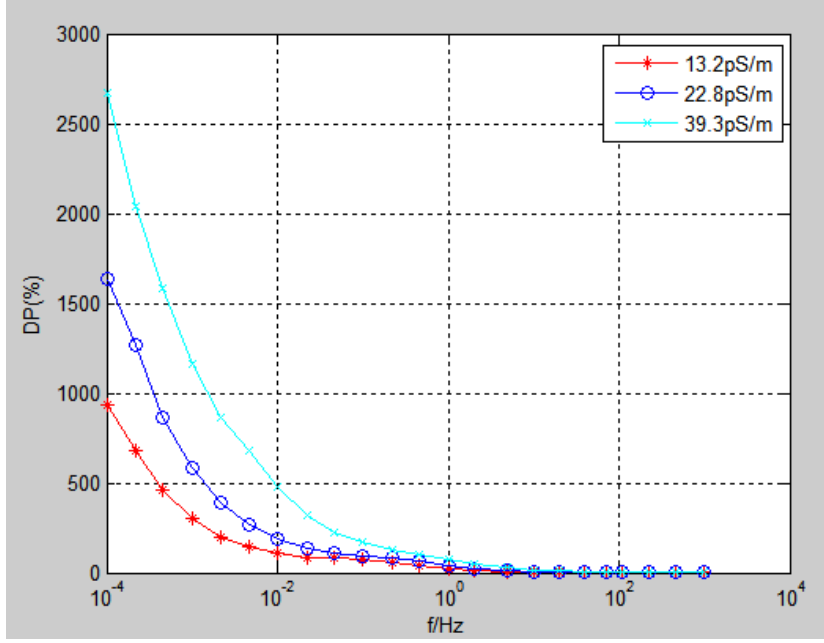

Fig.9 Dissipation factor with different oil conductivity. 


\subsubsection{Influence of aging oil}

Discharges of partial tensions in oil and thermal stress contribute greatly to it's aging and depending on the time of aging present in different dielectric responses [20, 24]. The graphs of figure (10) e (11) show different dielectric responses of oil aged at different aged time intervals having the dissipation factor and capacitance curve tends to shift to the right with increasing frequencies. The oil was aged at a temperature of $120^{\circ} \mathrm{C}$. Therefore, aging implies an increase in oil conductivity and a loss of its dielectric strength. The dielectric losses occur at low frequencies as shown in the capacitance and dissipation factor graphs.

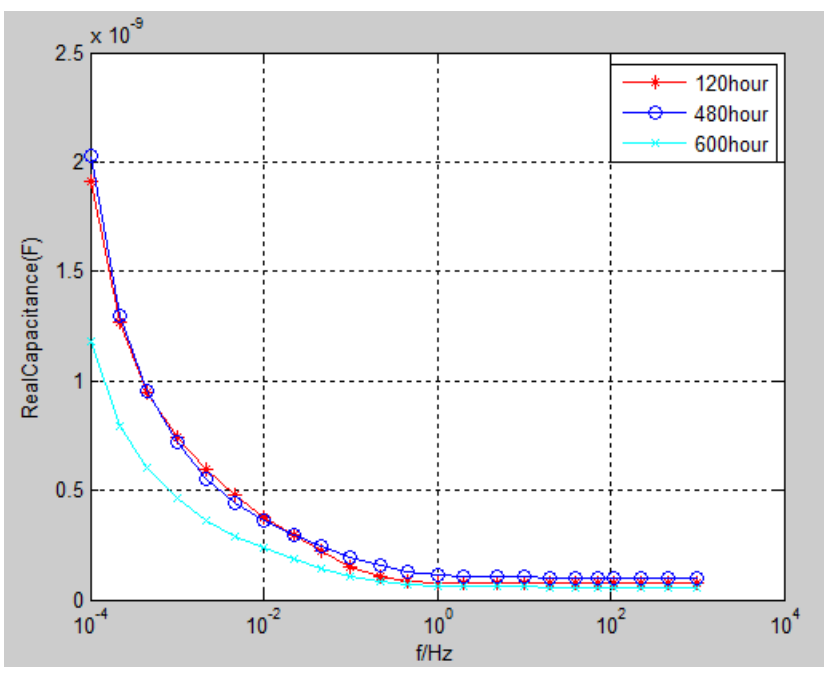

a) The Real part of capacitance at a different time aged.

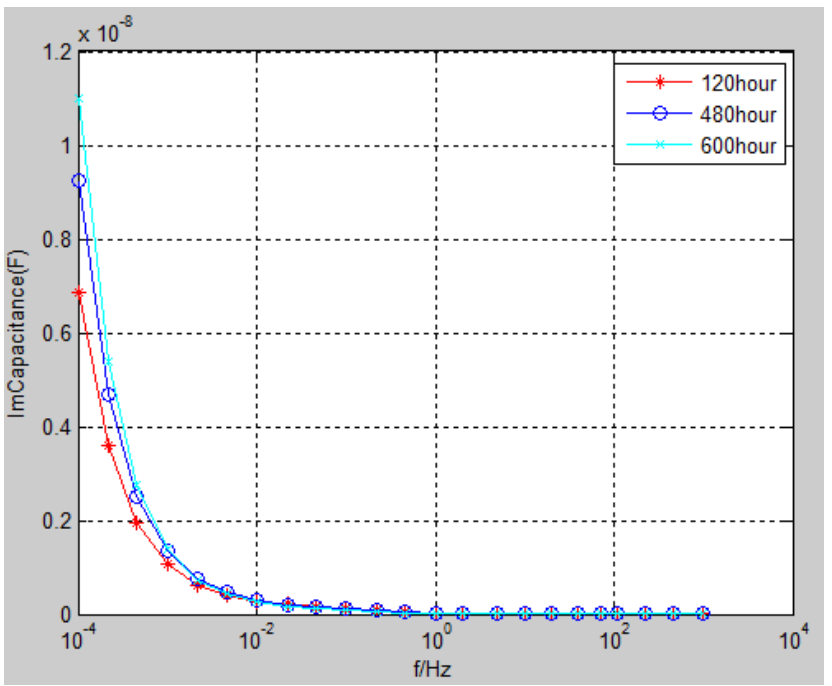

b) The imaginary part of capacitance in different time aged

Fig.10 Complex capacitance in different time aged

This publication is licensed under Creative Commons Attribution CC BY. http://dx.doi.org/10.29322/IJSRP.11.05.2021.p11318

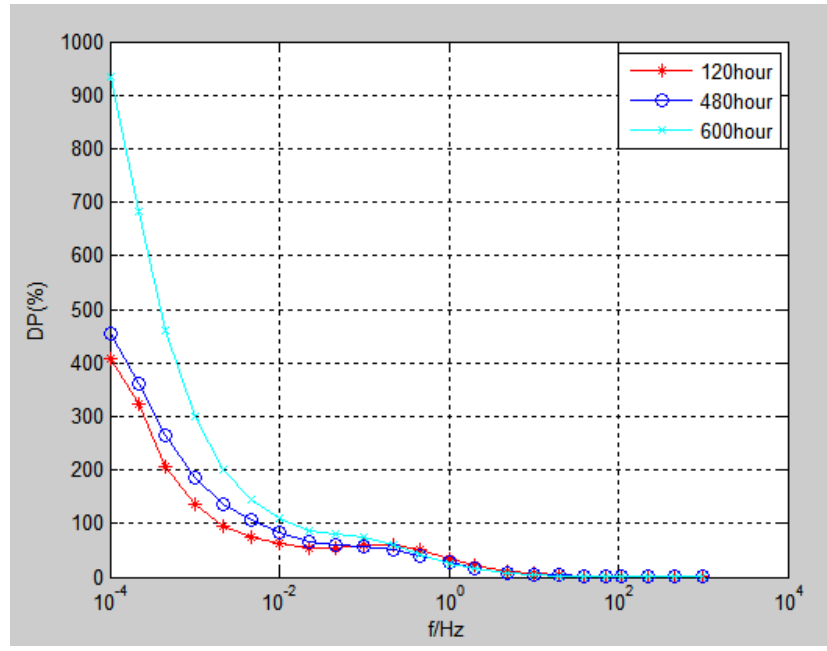

Fig.11 Dissipation factor in different time aged.

\section{DISCUSSION OF RESULTS}

The dielectric response in a wide frequency range of insulation systems of power transformers allows the analysis of the influence of the temperature, moisture, conductivity, and aging of oil. With increasing temperature, moisture content, or aging of oil, the curve of the DF and complex capacitance increases to the higher frequencies. The graphs of the dielectric responses for both capacitance and the dissipation factor show that the influence of cellulose moisture, temperature, conductivity, and oil aging has a greater influence at low frequencies.

\section{CONCLUSION}

Dielectric diagnostic methods deduce moisture in a paper of insulation system of power transformers, from dielectric properties such as polarization and depolarization currents (PDC method), complex capacitance, and the dissipation factor (FDS method), in this paper is analyzed only the FDS method using complex capacitance and dissipation factor. Aging effects due to moisture content and temperature will change these quantities in different frequency ranges. With the increasing moisture content, aging, or temperature, in the insulation system of power transformers, the curve of the dissipation factor shifts towards the higher frequencies. Moisture influences in the curve of the dissipation factor at low-frequency and high-frequency range, but his effect is more noticeable in the low-frequency. The increase in the conductivity of the oil implies an increase in the dissipation factor and the consequent displacement of the graph to the right with the increase in frequency and this displacement are more accentuated at low-frequencies. The effects of moisture, oil conductivity, and temperature according to the measurement results show that have more effect at lowfrequencies $(0.001 \mathrm{~Hz}$ to $100 \mathrm{~Hz})$, Utilizing this range of the frequency is possible to save time to get the dielectric response. 


\section{REFERENCES}

[1]. Maik Koch Michael Krüger, "The negative dissipation factor and the interpretation of the dielectric response of power transformers", 16th International Symposium on High Voltage Engineering, Austria, Series A, Vol. 73, Iss. 3, 2014, , pp 402-422

[2]. Belén García, et al "Determination of water content in transformer solid insulation by frequency-domain spectroscopy", proc. of the 5th wseas/iasme int. conf. on electric power systems, high voltages, electric machines, tenerife, spain, december , 2015,pp16-18

[3]. Michael Krueger1, et al "Dielectric Response Analysis and PD Testing for Condition Assessment of HV Bushings", OMICRON, USA, 2015

Journal article

[4]. Michael Jaya, Thomas Leibfried, "Information within the Dielectric Response of Power Transformers for Wide Frequency Ranges", present at IEEE International symposium on electrical insulation, CA, EUA, Vol. 70, Iss. 3, 2014, 2010, pp 101-120

[5]. T. K. Saha, et al, "Understanding Frequency \& Time Domain Polarisation Methods for the Insulation Condition Assessment of Power Transformers",present at IEEE 2009 IEEE Power \& Energy Society General Meeting, AB, Canada, Vol. 7, 2009, , pp 202-222

[6]. Raj B. Jadav, et al, "Dielectric Response of Transforme InsulationComparison of Time Domain and Frequency Domain Measurements" present at Conference Proceedings IPEC, IEEE, Singapure, Vol. 10,2010, pp 82-92

[7]. Matz Ohlen, Peter Werelius "Dielectric Frequency Response and Temperature Dependence of Power Factor", present at IEEE International Symposium on Electrical Insulation, CA,USA,Vol. 3, 2014, pp 92-102

[8]. Jun Liu, Hua Wang, et al, "Influence of Geometry to Dielectric Frequency Responses of Oil-paper Insulation", 2013 IEEE International Conference on Solid Dielectrics (ICSD), Vol. 83, 2013 ,Bolagano, Italy pp 32-42

[9]. Kapila Bandara, Chandima Ekanayake, et al "Modelling the Dielectric Response Measurements of Transformer oil" IEEE Transactions on Dielectrics and Electrical Insulation, Volume: 22 , Issue: 2 , April 2015, pp 1283 - 1291.

[10]. Ricardo Scholz, "Avaliação do comportamento dielétrico dos materiais isolantes utilizados em transformadores de distribuição por meio de espectroscopia dielétrica", $\mathrm{PhD}$ dissertation, graduete progra, in engieeering and materiais,Uniparana, 2013, pp21-30

[11]. ABB, "Advanced diagnostics provide a complete health check for power transformers", technical note, 2014.pp12-15.

[12]. Jaime Sune , Leonardo A. Heredia at al, "Guia de Manutencao para Transformadores de Potencia", cigre, brasil,2015, pp34-40

[13]. Mahdi Khanali, Shesha Jayaram, "Dielectric Frequency Response of Transformer Insulation System under High-dV/dt Stresses", present at IEEE 11th International Conference on the Properties and Applications of Dielectric Materials,Sydney, NSW, Vol. 13, Australia, 2015, pp-128-134

[14]. A. Baral and S. Chakravorti, "Prediction of Moisture Present in Cellulosic Part of Power Transformer Insulation using Transfer Function of Modified Debye Model", IEEE Transactions on Dielectrics and Electrical Insulation Vol. 21, No. 3; June 2014,pp 1368 - 1375

[15]. Peter Werelius, Jialu Cheng, et al, "Dielectric Frequency Response Measurements and Dissipation Factor Temperature Dependence", present at IEEE International Symposium on Electrical Insulation, , San Juan, PR, USA , Vol. 3, 2012, pp123-137.

[16]. Jaime Sune , Leonardo A. Heredia at al, "Guia de Manutencao para Transformadores de Potencia", cigre, brasil,2015, pp21-29

[16]. Matz Ohlen, Peter Werelius, "Dielectric Frequency Response and Temperature Dependence of Power Factor", present at IEEE International
Symposium on Electrical Insulation, San Diego, CA, USA, Vol. 15 2015, pp7886

[17]. Maik Koch, Thomas Prevost, "Analysis of Dielectric Response Measurements for Condition Assessment of Oil-Paper Transformer Insulation", IEEE Transactions on Dielectrics and Electrical Insulation Vol. 19, No. 6; December,2012, pp 1908 - 1915,

[18]. Peter Werelius, et al, "Dielectric Frequency Response Measurements and Dissipation Factor Temperature Dependence" present at IEEE International Symposium on Electrical Insulation, San Juan, PR, USA, Vol. 83, 2012. Pp258-

[19]. A. Bassetto Filho, "Avaliação da Umidade do Isolamento Sólido de Transformadores de Potência", present at II congresso de inovacao tecnologia em energia electrica. Sp, Barazil, Vol. 3 2015, pp536-54

[20]. Mihai Răzvan MITROI1 Ciprian ilies , "Analysis of insulation system of power transformers polarization/depolarization currents method" - UPB Scientific Bulletin, Series A: Applied Mathematics and Physics, ., Series A, Vol. 73, Iss. 3, 2011, pp 502-512

[21]. Matz Ohlen, Peter Werelius "Dielectric Frequency Response and Temperature Dependence of Power Factor" present at IEEE International Symposium on Electrical Insulation, San Diego, CA,2010, USA, Vol 7, pp201213

[22]. Wojciech Sikorski,et al "Moisture Migration in an Oil-Paper Insulation System in Relation to Online Partial Discharge Monitoring of Power Transformers”Energies,vol 9,2016, pp1082-1099

[24]. Jalal M. Abdallah, "Investigating the Transformer Operating Conditions for Evaluating the Dielectric Response" World Academy of Science, Engineering and Technology International Journal of Electrical and Computer Engineering Vol:5, No:3, 2011,pp 70-82

\section{AUTHORS}

Antonio Tome Mandala - was born in Mozambique in 1989, received his B.S degree in electrical engineering from the Institute Polytechnic of Songo, Mozambique in 2014, and M.Sc. in electric engineering in Technologic University of Havana, Cuba in 2017. Currently he is PhD student in China Three Gorges University, Yichang, China. His research interests are condition monitoring and fault diagnosis in power equipment.

Zhang Tao - received his B.S degree in computer science and technology from the Henan Polytechnic University, China, in 2004, and $\mathrm{PhDs}$ in electric engineering in from Fuzhou University, China, in 2010. He is currently a professor in China Three Gorges University, Yichang, China. His current research interests include optimization of power systems, condition monitoring and fault diagnosis of power equipment

Jiang Shieje - his B.S degree in electrical engineering in Herbin University China, currently he is master student in China Three Gorges University, Yichang, China. His research interests are condition monitoring and fault diagnosis in power equipment.

Zhang Ning - - his B.S degree in electrical engineering, currently he is master student in China Three Gorges University, Yichang, China His research interests are condition monitoring and fault diagnosis in power equipment. 
Correspondence Author - Antonio Tome Mandala, eng.mandala@gmail.com, +8613235623541 